\title{
THE STAPEDIAL MORPHOLOGY OF THE XENARTHRA AND ITS IMPLICATIONS FOR HIGHER-LEVEL MAMMALIAN RELATIONSHIPS
}

GAUDIN*, Timothy J., Dept. of Organismal Biology \& Anatomy, University of Chicago, 1025 E. 57th St., Chicago, IL, 60637, U.S.A.; TURNBULL, William D., Dept. of Geology, Field Museum of Natural History, Roosevelt Rd. at Lake Shore Dr., Chicago, IL, 60605-9410, U.S.A.

The mammalian order Xenarthra (including the living Neotropical armadillos, anteaters, and tree sloths) has figured importantly in recent hypotheses of interordinal relationships among eutherian mammals. It has been suggested that the group shares a common ancestry both with the extant Old World order Pholidota (i.e. the pangolins or scaly-anteaters) and the extinct North American group Palaeanodonta. Furthermore, these three groups have been linked together into a monophyletic Cohort Edentata, which has been hypothesized to represent the sister-group to all other eutherians. This placement of edentates relative to the remainder of Eutheria has been supported in part by a purported difference in the morphology of the stapes in the two groups- edentates possessing a primitive, imperforate/columelliform morphology, other placentals a derived, perforate/stirrup-shaped morphology.

A recent study of stapedial morphology among mammals by Novacek and Wyss (1986) suggests that within the Xenarthra itself a perforate stapes is found among armadillos, but that the pilosa in particular (the clade including anteaters and sloths) and the order as a whole are characterized primitively by an imperforate stapes. Our studies of the xenarthran ear region (Patterson et al., in press) have uncovered new ontogenetic and paleontological evidence which contradict the findings of Novacek and Wyss. Among adults of the two extant tree sloth genera, the stapes lacks a stapedial foramen. However, in both genera, this adult imperforate morphology is derived from a perforated juvenile stapes. Novacek and Wyss ignored fossil species in their consideration of the xenarthran stapes. It has long been known that extinct ground sloths of the family Mylodontidae possessed a large stapedial foramen. Unfortunately, until now no stapes were known from the remaining ground sloth families, the Megatheriidae and the Megalonychidae.We have uncovered a complete left stapes of an early Miocene megatheriid ground sloth Eucholoeops ingens. This stapes possesses a well-developed stapedial foramen. We believe that this new paleontological evidence, combined with our information on the ontogeny of the stapes in the living genera, clearly indicates that a perforate stapes is primitive for sloths. Moreover, when we plot distributions of stapedial morphologies of both living and fossil edentates onto a phylogeny of the Edentata, we can demonstrate that the a large stapedial foramen is primitive for the Xenarthra as a whole, and probably for the entire Cohort Edentata. Such a distribution makes it unlikely that stapedial morphology can be used to separate edentates from other eutherian mammals.

Novacek, M.J. and A.R. Wyss. 1986. Origin and transformation of the mammalian stapes, p. 35-53. In K.M. Flanagan and J.A. Lillegraven (eds.), Vertebrates, Phylogeny and Philosophy. Contributions to Geology, University of Wyoming, Special Paper 3.

Patterson, B.P., W.S. Segall, W.D. Turnbull, and T.J. Gaudin. (in press). The ear region in xenarthrans (=Edentata, Mammalia). Part II. Pilosa. Fieldiana, Geology. 